\title{
Postpancreatoduodenectomy Hemorrhage: Association between the Causes and the Severity of the Bleeding
}

\author{
Safi Khuria, bubhi Mansour ${ }^{a} \quad$ Amir Obeid $^{a} \quad$ Ameer Azzam $^{c}$ \\ Guiseppe Borzellino ${ }^{d}$ Yoram Klugera, b \\ aDepartment of General Surgery, Rambam Health Care Campus, Haifa, Israel; ${ }^{b}$ HPB and Surgical Oncology Unit, \\ Rambam Health Care Campus, Haifa, Israel; ' Emergency Medicine Department, Rambam Health Care Campus, \\ Haifa, Israel; ' ${ }^{\mathrm{G}}$ General Surgery Department, Verona Hospital, Verona, Italy
}

\section{Keywords}

Pancreatoduodenectomy · Postpancreatoduodenectomy hemorrhage $\cdot$ Pseudoaneurysm

\begin{abstract}
Introduction: Of the complications following pancreatoduodenectomy (PD), postpancreatoduodenectomy hemorrhage $(\mathrm{PPH})$ is the least common, but severe forms can be life-threatening without urgent treatment. While early $\mathrm{PPH}$ is mostly related to surgical hemostasis, late PPH is more likely due to complex physiopathological pathways secondary to different etiologies. The understanding of such etiologies could therefore be of great interest to help guide the treatment of severe, potentially life-threatening, late PPH cases. Objective: The aim of this retrospective study was to assess the causes of PPH as a complication and explore a possible association between the causes and the severity of late PPH. Methods: A retrospective study was performed at the HPB and Surgical Oncology Unit, Rambam Health Care Campus, Haifa, Israel. The charts of all patients submitted for PD were reviewed, and all patients with $\mathrm{PPH}$ were included. The timing, cause, and severity of PPH as well as other information were collected. A statistical analysis on the possible association between cause and severity of late $\mathrm{PPH}$ was performed. Results: A total of 347 patients underwent PD, 18 of whom (5.18\%) developed PPH. Early PPH was reported in 1 patient
\end{abstract}

(5.6\%) with severe bleeding from the gastric staple line. Late $\mathrm{PPH}$ was reported in 17 patients (94.4\%). The most common causes of late PPH were bleeding from a vascular pseudoaneurysm (PSA) reported in 6 patients, 1 with mild and 5 with severe hemorrhage, and bleeding from a gastroenteric anastomosis marginal ulcer reported in 6 patients, all with mild hemorrhage. No etiology was found in 5 patients with mild hemorrhage. A significant association was found between the severity of late hemorrhage and vascular PSA as the cause of the bleeding $(p=0.001)$. All PSA bleeding occurred in cases complicated by a postoperative pancreatic fistula (POPF), with a significant statistical association $(p<0.001)$. Conclusions: The most common cause of PPH was bleeding from a vascular PSA; the majority of these cases involved severe bleeding with late presentation, and all were associated with a POPF formation. In such cases, early detection by computed tomography angiography is mandatory, thereby promoting urgent treatment by angiography of vascular bleeding complications following PD.

(C) 2020 S. Karger AG, Basel

\section{Introduction}

Pancreatoduodenectomy (PD) is a complex, highly challenging operation to perform. The first successful 1 -stage PD was reported by Allen Whipple in 1945, when 
he successfully anastomosed the pancreatic duct to the jejunum [1]. Although Whipple was the first to report the single-stage PD procedure, Verne Hunt was the first surgeon to successfully restore pancreaticoenteric anastomosis following PD in 1941 [2]. PD is the surgical procedure of choice for the treatment of benign and malignant diseases of the periampullary region (the head of the pancreas, ampulla of Vater, distal common bile duct, and second part of the duodenum), severe trauma to the pancreatic head and duodenum, and highly selective cases of chronic pancreatitis $[3,4]$. The mortality rate following PD was initially high at almost $25 \%$, but, as a result of the development of specialized centers, along with the improvement in perioperative care and advances in surgical techniques, mortality rates have fallen to $<1 \%$, especially in high-volume centers [5-8]. Nevertheless, the morbidity rate following PD remains high, with almost $30-40 \%$ of patients developing $\geq 1$ complication $[9,10]$. The most common complications following PD are delayed gastric-emptying, postoperative pancreatic fistula (POPF), intra-abdominal collections, biliary anastomotic leakage and post-PD hemorrhage (PPH), the last being the least frequent to occur. The incidence rate of PPH is 5-16\%, with severe bleeding occurring in $<10 \%$ of patients. The condition may be lifethreatening if urgent treatment is not performed, and it is usually associated with high morbidity and mortality, especially if surgical intervention is required $[11,12]$.

According to the International Study Group of Pancreatic Surgery (ISGPS), PPH can be classified into early and late PPH $[13,14]$. While early PPH is mostly related to surgical hemostasis, late $\mathrm{PPH}$ is more likely due to more complex physiopathological pathways. $\mathrm{PPH}$ that develops early following the index operation can be due to bleeding vessels (branches of the portal vein or the superior mesenteric artery [SMA]), or bleeding from one of the anastomoses. Late PPH could be due to a marginal ulcer (mostly at the gastroenteric anastomosis) or a bleeding vascular pseudoaneurysm (PSA), mostly involving the gastroduodenal artery (GDA) stump, and may develop following pancreatic leak and vessel erosion [15].

The understanding of the etiology of such a pathway could therefore be of great interest in cases of severe hemorrhage to guide the treatment of a potentially life-threatening condition that could be otherwise preventable. The aim of this retrospective study was to assess the cause of $\mathrm{PPH}$ as a complication and explore the possible association between the cause and severity of late PPH.

\section{Methods}

A retrospective study over a period of 8 years, from 1 January 2011 to 31 December 2018, was performed at the Hepato-Pancreato-Biliary (HPB) Unit of the General Surgery Department at Rambam Health Care Campus, Haifa, Israel. All patients aged $\geq 18$ years who underwent PD were included in the study. Patients who underwent PD for severe trauma to the pancreatic head or duodenum, or other forms of pancreatic resection such as distal or total pancreatectomy, were excluded from the study. Patients were checked for readmission to our hospital or to other medical centers.

The 3 main outcomes were: timing of onset, cause of hemorrhage, and severity of hemorrhage. Other data included clinical manifestation of the hemorrhage, investigational modules used for diagnosis, management, and mortality rate. Possible risk factors for PPH relating to both surgical complications (e.g., POPF, intraabdominal abscess) and the patient (e.g., anticoagulant or antiaggregant therapy and final pathology) were also registered.

Timing of PPH was classified according to the ISGPS, into early and late PPH; early is when the bleeding occurs within $24 \mathrm{~h}$ of the index operation and late is when bleeding develops $>24 \mathrm{~h}$ after it $[14,15]$.

Causes of PPH were defined by the lesion found at the site of the bleeding. The cause was classified as unknown when no bleeding site was found on CT scan or endoscopy according to the clinical manifestation of the bleeding.

The severity of the hemorrhage was classified according to the ISGPS criteria into: mild PPH in case of small-medium blood loss (a decrease in hemoglobin level $<3 \mathrm{~g} / \mathrm{dL}$ ) which leads to mild clinical impairment, and severe PPH (a decrease in hemoglobin level of $\geq 3 \mathrm{~g} / \mathrm{dL}$ ) which usually results in hemodynamic instability [14, $15]$.

The cases of POPF were registered according to the classification reported by Bassi et al. [16], with grade A POPF being replaced by biochemical leak.

Since it is in late PPH that the knowledge of a possible association between the cause and severity of PPH could be of interest in planning treatment, this association was statistically tested by comparing the respective frequency of causes in patients with mild $\mathrm{PPH}$ and patients with severe PPH.

The role of possible risk factors for $\mathrm{PPH}$ was investigated by comparing their frequency in patients without $\mathrm{PPH}$ and patients with $\mathrm{PPH}$ in a univariate analysis. The analysis was completed by investigating a possible association between clinically relevant potential risk factors, such as surgical complications and PSA as major causes of late $\mathrm{PPH}$, by comparing the respective rates in patients with and without bleeding PSA.

Continuous variables are summarized as mean and SD and discrete variables are categorically expressed as $n$ (\%). Student's $t$ test was used for continuous variables. The $\chi^{2}$ or Fisher's exact test, depending on the results, was used for variables that were dichotomous. A $p$ value $<0.05$ was considered significant.

\section{Results}

During the study period, 347 patients underwent PD for the management of diseases in the periampullary region. $\mathrm{PPH}$ was registered in 18 patients (5.2\%), 10 males and 8 females (ratio 1.25:1). The average age was 68 years (range 22-85 years).

As reported in Table 1 and Figure 1, the timing of the bleeding was early in 1 patient (5.6\%), and late in 17 (83.3\%). The patient with early PPH had severe bleeding from the gastric staple line. In the cases of late PPH, the most common causes were bleeding from a vascular PSA 
Table 1. Summary of timing, site of bleeding, and severity of PPH

\begin{tabular}{lccc}
\hline & Mild & Severe & Total \\
\hline $\begin{array}{l}\text { Early } \\
\quad \text { Gastric stapler line }\end{array}$ & 0 & 1 & 1 \\
$\begin{array}{l}\text { Late } \\
\quad \text { Pseudoaneurysm }\end{array}$ & 1 & 5 & 6 \\
$\quad$ Marginal ulcer & 6 & 0 & 6 \\
$\quad$ Unknown & 5 & 0 & 5 \\
\hline Total & 12 & 6 & 18 \\
\hline
\end{tabular}

in 6 patients ( 1 with mild and 5 with severe hemorrhage) and bleeding from a gastroenteric anastomosis marginal ulcer in 6 patients (all with mild hemorrhage). No etiology was found in 5 patients with mild hemorrhage. Overall, hemorrhage was mild in $12(66.6 \%)$ and severe in 6 (33.3\%) patients. According to the ISGPS classification, no Grade A bleeding was observed, 13 patients had Grade $B$ bleeding, and 5 had Grade $C$ bleeding.

Blood discharge from the drain was the most common presentation and was reported in 11 patients (61.1\%). As our routine practice, 2 Jackson-Pratt drains are placed in the abdominal cavity of all patients undergoing PD. These are stationed in the right upper abdominal space near the pancreatico- and hepatico-jejeunal anastomosis. Patients are usually discharged with the drains and then followed up at our outpatient clinic a week later. Of these patients with blood discharge from the drain, 8 had been previously diagnosed with POPF, and none had sentinel bleeding into the drains upon their discharge. A total of $7 \mathrm{pa}$ tients (38.9\%) presented with signs of upper gastrointestinal bleeding, with hematemesis reported in 6 and a continuous bloody discharge from the nasogastric tube in the remaining patient.

The patient with early severe hemorrhage was hemodynamically unstable. Urgent surgery was performed. Active bleeding from the gastric staple line was found and a hemostatic suture was used to stop the bleeding. During $\mathrm{PD}$ at our center, gastroenterostomy anastomosis is performed by means of a circular staple inserted through an anterior wall gastrostomy, which is, in turn, closed with a linear staple afterwards.

In the cases of late PPH, vascular PSA was the cause of bleeding in 6 patients, involving the GDA in 5 cases and the inferior pancreaticoduodenal artery in 1 . One was a mild case and 5 involved severe hemorrhage. Computed tomography angiography (CTA) was diagnostic for all cases of bleeding PSA, which indicates a high specificity of this exam in the diagnosis of $\mathrm{PPH}$. All patients were successfully treated by means of angiographic embolization using different methods.

Post-Pancreatectomy Hemorrhage

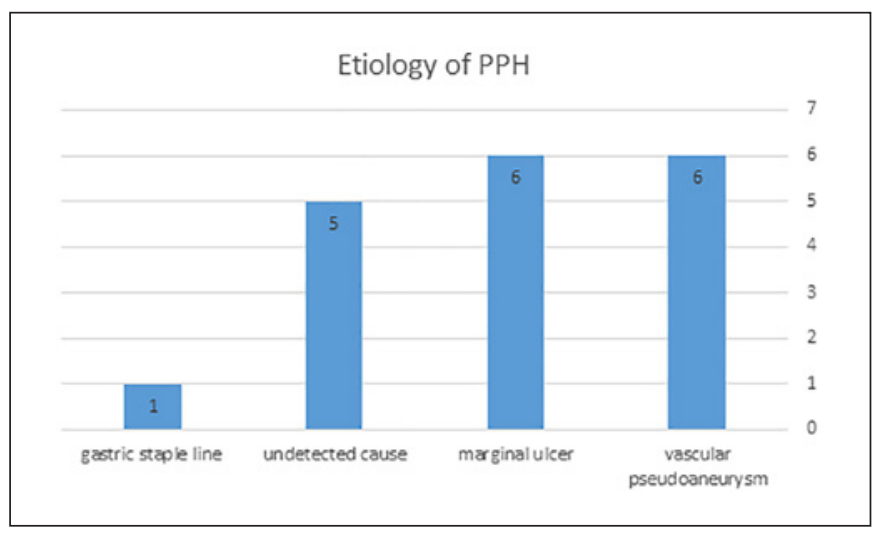

Fig. 1. Distribution of causes of $\mathrm{PPH}$.

Bleeding from a marginal ulcer of the gastroenteric anastomosis was found in 6 patients, all of whom had undergone PD with a Roux-en-Y reconstruction. $\mathrm{PPH}$ was late with mild hemorrhage in all of them. All were treated by endoscopy and had an average of 2 units of packed red blood cells (PRBC) transfused.

All patients with bloody discharges from the drain and an unknown etiology upon completing a hemorrhage screen workup presented as late PPH. A negative CTA scan and negative endoscopy were reported in 4 cases, while no diagnostic tests were performed in 1 case of limited bloody discharges from the drain. All cases were treated conservatively, with transfusion of an average of 3 units of PRBC per patient. In all cases, the bleeding responded to conservative treatment, leaving no merit to performing a surgical intervention.

Urgent surgery was performed in 1 patient due to hemorrhagic shock. Urgent CTA was performed in 10 patients with bloody discharge from the drain. Urgent endoscopy was performed in 6 patients with gastrointestinal bleeding. In 1 patient with mild hemorrhage, no diagnostical tests were performed. No mortality was registered due to $\mathrm{PPH}$.

For the statistical analysis evaluating the association between the cause and severity of PPH, no severe bleeding from marginal ulcers and no severe unknown hemorrhage were diagnosed, so no $\chi^{2}$ test was conducted. By grouping unknown etiology with marginal ulcer bleeding, PSA was found to be significantly associated with severe hemorrhage. The rate of PSA was $100 \%$ in patients with severe bleeding compared to $8.3 \%$ in patients with mild hemorrhage ( $p=0.001$, Fisher's exact test).

As reported in Table 2, no significant association was found between possible risk factors for PPH (whether relating to surgical complications or patients) and the incidence rate. The overall rate of POPF was $26 \%$, but this complication occurred in $8(44.4 \%)$ patients with $\mathrm{PPH}$, all 
Table 2. A comparison between patients with and without PPH

\begin{tabular}{lccc}
\hline & Patients with PPH & Patients without PPH & $p$ value \\
\hline Number of patients & 18 & 329 & \\
Average age, years (range) & $68(22-85)$ & $64(19-86)$ & 0.16 \\
Male-to-female ratio & 1.25 & 1.27 & 0.97 \\
Anticoagulant/antiaggregant treatment & $15(83.3)$ & $279(84.8)$ & 0.87 \\
Roux-en-Y classic PD performed & $18(100)$ & $329(100)$ & 1 \\
POPF & $8(44.4)$ & $82(24.9)$ & 0.07 \\
Intra-abdominal abscess & $2(11.1)$ & $36(10.9)$ & 1 \\
\hline Pathology & & & 0.64 \\
PDA & $10(55.5)$ & $201(61.1)$ & 0.73 \\
IPMN high-grade dysplasia & $3(16.7)$ & $46(14)$ & 0.44 \\
IPMN low-grade dysplasia & $1(5.6)$ & $29(8.8)$ & 0.42 \\
Neuroendocrine tumor & $1(5.6)$ & $9(2.7)$ & 0.42 \\
Duodenal adenocarcinoma & $1(5.6)$ & $9(2.7)$ & 0.38 \\
Distal CBD/ampulla adenocarcinoma & 0 & $26(7.9)$ & 1 \\
Pancreatic papillary pseudotumor & 0 & $2(0.6)$ & 0.07 \\
Normal pancreas & $2(11.1)$ & $7(2.1)$ & \\
\hline
\end{tabular}

Values express $n$ (\%), unless otherwise indicated. PPH, postpancreatectomy hemorrhage; PD, pancreatoduodenectomy; PDA, pancreatic ductal adenocarcinoma; IPMN, intraductal papillary mucinous neoplasm; CBD, common bile duct; POPF, postoperative pancreatic fistula.

of whom had a biochemical leak. Although the difference in the rate of POPF in patients with and without $\mathrm{PPH}$ was $19.4 \%$, the association between POPF and PPH was not statistically significant $(p=0.07)$; however, the estimated power of such a comparison is $<50 \%$. Moreover, although $\mathrm{POPF}$ was not found to be a risk factor for $\mathrm{PPH}$, all patients who bled due to PSA were initially diagnosed with a biochemical leak (previously POPF grade A, according to the ISGPF definition of POPF). The association between POPF and PSA was found to be statistically significant with a POPF rate of $100 \%$ in patients with bleeding PSA and $26 \%$ in patients with no bleeding PSA $(p<$ 0.001 ), suggesting the potential role of POPF in the development of a bleeding PSA as a cause of late PPH.

\section{Discussion}

The results of this study show that most of the patients suffered from late $\mathrm{PPH}$, and that bleeding vascular PSA was the most common cause of severe late $\mathrm{PPH}$. Moreover, a significant association was found between vascular PSA bleeding and an initial diagnosis of POFP.

It was a retrospective study, but all consecutive patients treated in the period already mentioned were included. Data are stored in a database that allows easy selection of cases of interest based on diagnosis, intervention, and postoperative complications. Rambam Health Care Campus is a referral center for 10 other hospitals that give medical cover for 2 million citizens, particularly all patients for whom major pancreatic surgery is indicated. Our study should therefore be considered as having a low risk of selection bias.

Some concern should be advocated about the cases for which no etiology was found. A recent meta-analysis reported a sensitivity of $56 \%$ for CTA in identifying the source of bleeding following pancreatectomy [17], so the high incidence of false-negative diagnoses could affect the association found between several causes of late severe bleeding. No details about the original studies were provided in the meta-analysis, but the low sensitivity of CTA scan in diagnosing vascular PSA could be explained by the intermittent characteristics of the bleeding in cases of $\mathrm{PPH}$ [18]. Data on gastrointestinal bleeding reported in a recent review suggest that, in cases of massive gastrointestinal bleeding, the sensitivity and specificity of CTA scan are much higher. Moreover, a negative CTA scan could be considered a good prognostic result, as patients with no bleeding evident on the scan are unlikely to have massive bleeding [19]. This observation may be valid for gastrointestinal bleeding, but no data on PSA as a cause of PPH were found. According to a recent review, a selflimiting episode of bleeding, so-called sentinel bleeding, may be the initial manifestation of PPH [18]. In these cases, CTA scan may also be negative, but extra caution must be exercised due to the fact that sentinel bleeding may precede a severe $\mathrm{PPH}$ in $50-80 \%$ of cases, thus requiring intensive monitoring and specific diagnostic workup. In our series, the cases of bleeding with an unknown origin should not be considered as sentinel bleeding since they 
were all self-limited and no further hemorrhage was observed in any of them.

Recent published studies on PPH have no homogenous methodology. A literature research limited to the past 10 years found studies reporting $\mathrm{PPH}$ complicating a series of pancreatectomies [20-26]. Others, like this study, have focused on PD [27-33], and some report results mainly related to late $\mathrm{PPH}[26,30,32]$. Other studies produced results about the treatment of PPH cases [34$44]$ and focused mainly on series of late PPH. In 1 series, PPH was classified according to the timing as early, intermediate, or late, but the only reported cases were intermediate or late [45].

The reported rate of $\mathrm{PPH}$ varies from 3 to $16.8 \%$ across studies, i.e., those covering all types of pancreatectomy [20-26], and those focusing on PD [27-29, 31, 45]. Only a handful has reported a rate $>10 \%[21,24,26,29]$. All series also reported that late PPH occurred more frequently than early $\mathrm{PPH}$, with a rate $>75 \%$ compared to $90 \%$ in our study. Only 1 study from Italy [26] reported a rate of late presentation of $45 \%$. This particular study had the biggest series of pancreatectomies, 2,429 cases in 13 years; the lower rate of late PPH is related to the finding that $77 \%$ of the patients had Grade B bleeding. The overall rate of late $\mathrm{PPH}$ as a complication of pancreatic surgery varies from 2.3 to $13.1 \%$ in the more recent studies [20, $22,23,25-27,29-33]$. These results are comparable to previous studies included in a meta-analysis that reported an overall rate of late $\mathrm{PPH}$ of 3.3\% (range 1.6-12.3\%) [46].

Severe late PPH, classified as Grade C by the ISGPS, is, however, the less common type. In our study, $29.4 \%$ of late PPH cases were severe. The data reported in the literature ranges mainly from 26.6 to $53.8 \%$ [20, 22, 23, 25, $26,30-33$ ]. However, 1 small series of $87 \mathrm{PD}$ in over 3 years reported a rate of severe late $\mathrm{PPH}$ of $90 \%$ [27].

As recommended in a recent review, the best approach should be tailored based on the clinical manifestation and the timing and severity of the bleeding [18]. However, the cause of bleeding also plays a role in $\mathrm{PPH}$ treatment strategy. Intraluminal bleeding may be approached by endoscopy first, while CTA is preferred for extraluminal bleeding. In cases where the site of bleeding cannot be found at the first examination, a diagnostic workup should be completed [47]. Based on nonanalytic data, some authors suggest performing a CTA scan, even in cases of a diagnosed cause of intraluminal bleeding on endoscopy. The finding of a mild bleeding cause might distract the physician from further severe bleeding causes, which can delay intervention and worsen the outcome [18]. This conclusion is not confirmed by the data of our study.

In all cases of intraluminal bleeding, a cause was found at endoscopy. In the cases of extraluminal bleeding, the cause was found in only $6 / 10$ patients. In patients with no apparent cause of bleeding, a full thorough diagnostic workup was completed, with a negative endoscopy in all cases. All 4 of these patients manifested with self-limited bleeding with no clinical worsening of the $\mathrm{PPH}$.

Early PPH is usually due to the technical failure of hemostatic factors used during surgery, and it can be mild or severe. In our study, 1 patient developed early PPH, manifesting as a bloody discharge from the nasogastric tube. Due to continuous bleeding, along with a severe decrease in hemoglobin level, she underwent a reoperation, during which a bleeding from the gastric staple line was detected, a primary suture was placed, and the bleeding stopped.

Late bleeding could be due to marginal ulcers, or bleeding from the resection bed, the anastomosis, or the vascular stump, or an arterial PSA. The majority of our patients suffered from late $\mathrm{PPH}(94.4 \%)$, with a bleeding vascular PSA the most common cause of late severe bleeding (6/17 patients, 5 with a GDA PSA and 1 with an inferior pancreaticoduodenal artery PSA). Recent studies focusing on PD [27-33, 45] have confirmed that the GDA stump is the most common site of bleeding. However, the clear description of a PSA is not always reported, and it may not always be clear whether the bleeding indeed arose from direct leakage from the artery stump, or a PSA that formed after surgery. Of 7 PSA cases, an extravasation of contrast material (suggesting active bleeding) was observed in only 2 patients, and 2 others showed signs of active bleeding with no PSA reported [31].

As a result, the exact prevalence of PSA in cases of late PPH may be underestimated. The rate of PSA as a cause of late severe bleeding is reported to be $28.5-38.8 \%$ in late PPH [17-19, 35, 44]. A statistical association between PSA and bleeding has not yet been explored. The most interesting finding of our study was the statistically significant association between late severe bleeding and arterial PSA as a cause of bleeding. Moreover, $83.3 \%$ of severe bleeding was caused by PSA, and the second-most common site of bleeding was the pancreaticoduodenal artery, a rare site of bleeding that has previously been reported only as a sight of sporadic bleeding $[34,37,40]$.

Of the post-PD complications, POPF has been reported to increase the risk of $\mathrm{PPH}$ and has been associated with late bleeding in $48.1-78.5 \%$ of cases [ $30,31,45]$. Our finding of $44.4 \%$ of POPF in PPH could be considered congruous with the data reported in the literature.

Interventional radiology (IR) has become a valuable diagnostic approach, allowing a definitive treatment by embolizing or stenting bleeding arteries in cases of extraluminal PPH. All the cases in our study were treated successfully by IR. Whether embolization or stent placement insertion is performed depends mainly on the site of the bleeding as well as the length of the GDA stump. In cases of a short GDA stump, hepatic artery stenting to bypass the bleeding site is the preferred management method, 


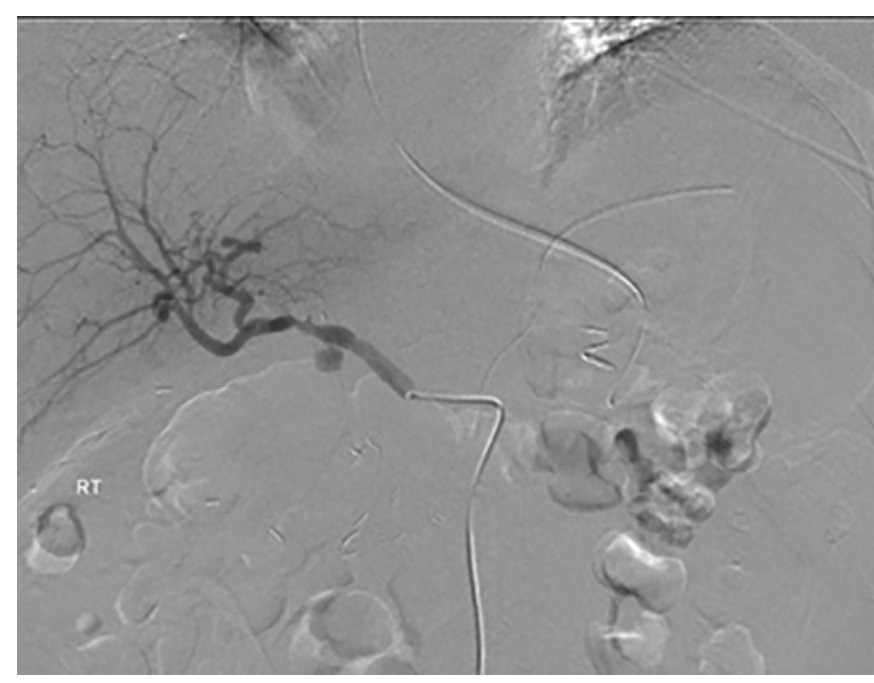

Fig. 2. Selective angiography of the celiac artery reveals PSA of the GDA (arrow).

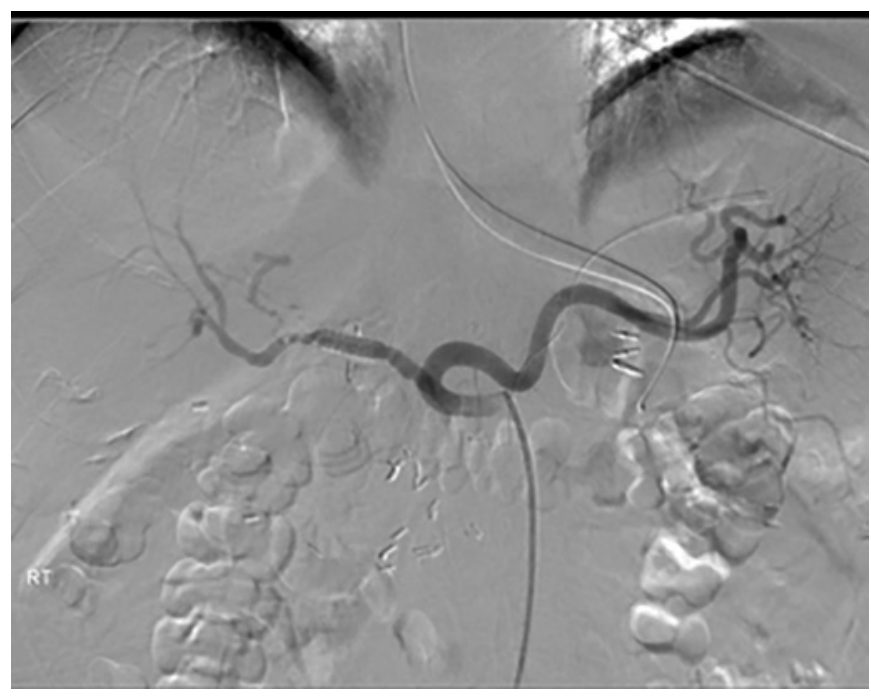

Fig. 3. Control of bleeding was achieved by stent insertion into the hepatic artery to bypass the PSA (arrow).

Table 3. Description of patients that presented with PPH due to bleeding vascular PSA

\begin{tabular}{|c|c|c|c|c|c|c|c|c|}
\hline $\begin{array}{l}\text { Case } \\
\text { No. }\end{array}$ & $\begin{array}{l}\text { Age, } \\
\text { years }\end{array}$ & Sex & $\begin{array}{l}\text { Indication } \\
\text { for PD }\end{array}$ & $\begin{array}{l}\text { Postoperative } \\
\text { complications }\end{array}$ & $\begin{array}{l}\text { Vascular } \\
\text { resection }\end{array}$ & Presentation & Findings on CTA & $\begin{array}{l}\text { Angiographic } \\
\text { management }\end{array}$ \\
\hline 1 & 80 & M & MD-IPMN & $\mathrm{PE}, \mathrm{BL}$ & No & hematemesis & PSA of the GDA & $\begin{array}{l}\text { stent graft into the CHA } \\
\text { (Fig. } 2,3 \text { ) }\end{array}$ \\
\hline 2 & 84 & M & PDA & $\mathrm{BL}$ & No & blood in drains & PSA of the GDA & stent graft into the $\mathrm{CHA}$ \\
\hline 3 & 67 & $\mathrm{~F}$ & LG-PIN & $\mathrm{BL}$ & No & blood in drains & $\begin{array}{l}\text { PSA of the GDA } \\
\text { (Fig. 4) }\end{array}$ & $\begin{array}{l}\text { coil embolization of the } \\
\text { CHA }\end{array}$ \\
\hline 4 & 68 & M & PDA & $\mathrm{BL}$ & No & hematemesis & no active bleeding & stent graft into the $\mathrm{CHA}$ \\
\hline 5 & 68 & M & PDA & $\mathrm{BL}$ & No & hematemesis & $\begin{array}{l}\text { active bleeding from } \\
\text { branch of SMA (Fig. 5) }\end{array}$ & glue embolization \\
\hline 6 & 74 & $\mathrm{~F}$ & PDA & $\mathrm{BL}$ & No & blood in drains & PSA of the GDA & stent graft into the $\mathrm{CHA}$ \\
\hline
\end{tabular}

M, male; F, female; PD, pancreaticoduodenectomy; MD-IPMN, main duct intraductral mucinous neoplasm; PDA, pancreatic duct adenocarcinoma; LG-PIN, low-grade pancreatic intraepithelial neoplasm; PE, pulmonary embolism; BL, biochemical leak; CTA, computed tomography angiography; PSA, pseudoaneurysm; GDA, gastroduodenal artery; IPDA, inferior pancreaticoduodenal artery; $\mathrm{CHA}$, common hepatic artery; SMA, superior mesentric artery.

while long GDA stumps are usually embolized with coils or glue (Table 3; Fig. 2-4). In 1 patient, the bleeding originated from a branch of the SMA, suspected to be the inferior pancreaticoduodenal artery stump (Fig. 5). This allowed a definitive treatment without major complications following the procedure. In the literature, the role of IR is well documented [34-44], but the reported success rate varies. Relapse bleeding, requiring more than an IR approach before treatment could be considered as definitive (reported in up to 47.6\%) [36-44]. A failure of IR was reported in up to $13 \%$ of cases in most of the studies $[34,36$, $38,41,43,44]$, with 1 [42] reporting a failure rate of $35 \%$.
Major hepatic complications have been reported in up to $23.8 \%$ of cases [48]. The risk of hepatic failure or hepatic abscess formation increased when performing an embolization of the hepatic artery following a pancreatectomy involving the head of the pancreas. In such cases, stenting is the preferred method of treatment.

Among $\mathrm{PPH}$ cases, a mortality rate ranging from 0 to $39.7 \%$ has been reported, and is associated with early $\mathrm{PPH}$, late $\mathrm{PPH}$, and treatment complications $[20,22,23$, $25,26,28-32,34,37-41,43-45]$. Studies focusing on late PPH report a mortality rate in the range of $7.1-23.8 \%$ [34, $37-41,43,44]$. In our study, no mortality was registered. 


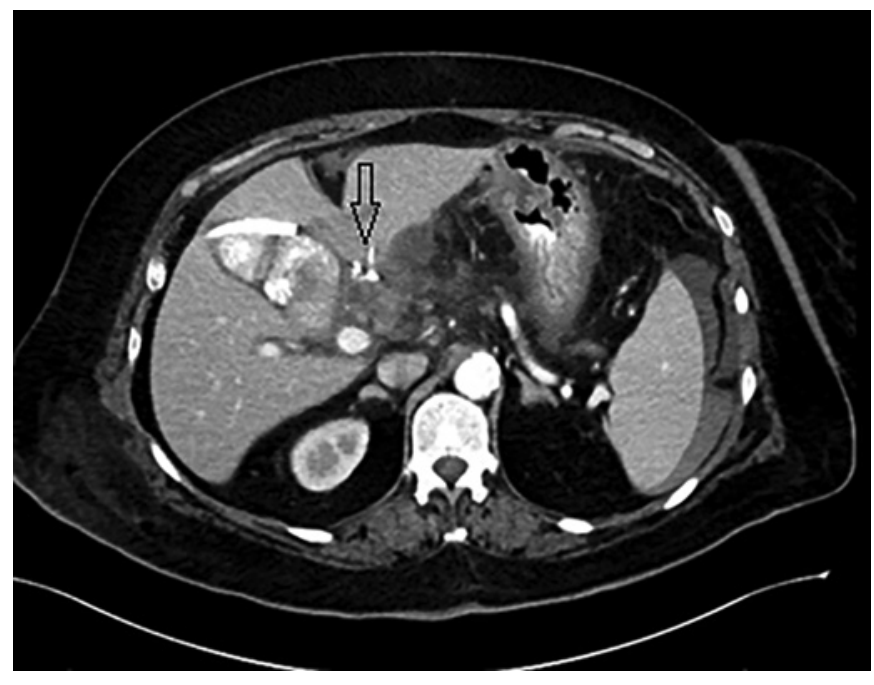

Fig. 4. On abdominopelvic CTA, a PSA of the GDA was demonstrated with contrast blush (arrow). A J-P drain inserted during operation can be seen next to the bleeding site.

The results of our study confirm most of the literature findings on $\mathrm{PPH}$ and include clinical presentations and late severe PPH treatment. A significant association between severe late PPH and PSA bleeding is of clinical importance. A finding of 1 PSA with mild bleeding suggests that PSA may form with no initial clinical importance but may nevertheless cause severe hemorrhage in the following stages. Although this would not alter the therapeutic approach, it should also be studied, to distinguish true PSA from bleeding secondary to arterial stump leakage.

\section{Conclusion}

PPH is a less common, yet well-known complication following $\mathrm{PD}$, with a wide range of incidence rates. A significant association was found between the cause and severity of the bleeding, with PSA as the cause of all severe cases of late $\mathrm{PPH}$, and a bleeding marginal ulcer as the cause of mild PPH. POPF was also found to be associated with PSA, which, in turn, was the major cause of late severe bleeding. In future studies, the distinction between true PSA and arterial stump leakage should be made.

\section{Statement of Ethics}

This article does not contain any experimental studies with human participants or animals performed by any of the authors. The study was approved by the Ethics Committee. Due to the retrospective nature of the study, informed consent was waived. The study was approved by the review board of our Department.

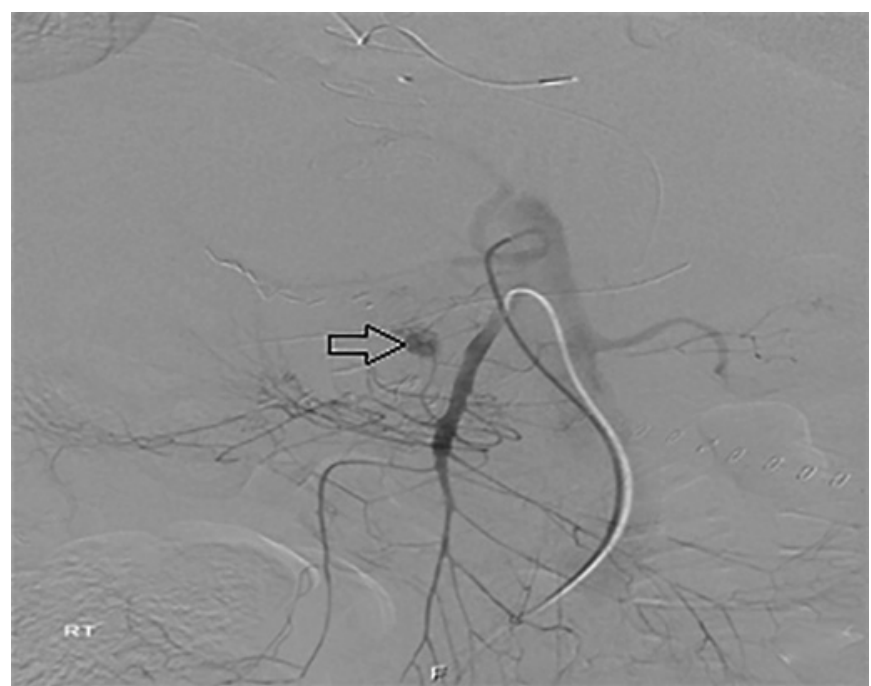

Fig. 5. Selective angiography of the superior mesenteric artery (SMA), showing an active bleeding from a branch of the SMA suspected to be from the inferior pancreaticoduodenal artery stump (arrow).

\section{Conflict of Interest Statement}

The authors have no conflicts of interest to declare.

\section{Funding Sources}

There were no funding sources.

\section{Author Contributions}

Acquisition of the data was made by Ameer Azzam and Amir Obeid and analysis and interpretation were done by Safi Khuri. The paper was drafted by Safi Khuri and Subhi Mansour, and critical revision and final approval of the published version was done by Yoram Kluger and Giuseppe Borzellino. All parties agree to be accountable for all aspects of the work in ensuring that questions related to the accuracy or integrity of any part of the work are appropriately investigated and resolved.

\section{References}

1 Whipple AO. Pancreaticoduodenectomy for Islet Carcinoma: A Five-Year Follow-Up. Ann Surg. 1945 Jun;121(6):847-52.

2 Hunt VC. Surgical Management of Carcinoma of the Ampulla of Vater and of the Periampullary Portion of the Duodenum. Ann Surg. 1941 Oct;114(4):570-602.

3 Courtney L. Scaife, Kelly C, Hewitt, Mary C. Mone, Heide J. Hansen. Edward T. Nelson. Sean J. Mulvihill. Comparison of intraoperative versus delayed enteral feeding tube placement in patients undergoing a Whipple procedure. HBP. 2014;16:62-9. 
4 Leichtle SW, Kaoutzanis C, Mouawad NJ, Welch KB, Lampman R, Hoshal VL Jr, et al. Classic whipple versus pylorus-preserving pancreaticoduodenectomy in the ACS NSQIP. J Surg Res. 2013 Jul;183(1):170-6.

5 Neoptolemos JP, Russell RC, Bramhall S, Theis B; UK Pancreatic Cancer Group. Low mortality following resection for pancreatic and periampullary tumours in 1026 patients: UK survey of specialist pancreatic units. $\mathrm{Br} J$ Surg. 1997 Oct;84(10):1370-6.

6 Shrikhande SV, Barreto SG, Somashekar BA, Suradkar K, Shetty GS, Talole S, et al. Evolution of pancreatoduodenectomy in a tertiary cancer center in India: improved results from service reconfiguration. Pancreatology. 2013 Jan-Feb;13(1):63-71.

7 Trede M, Schwall G, Saeger HD. Survival after pancreatoduodenectomy. One hundred eighteen consecutive resections without an operative mortality. Ann Surg. 1990;211(4):447-58.

8 Cameron JL, Pitt HA, Yeo CJ, Lillemoe KD, Kaufman HS, Coleman J. One hundred and forty-five consecutive pancreaticoduodenectomies without mortality. Ann Surg. 1993 May;217(5):430-5.

9 Bassi C, Falconi M, Salvia R, Mascetta G, Molinari E, Pederzoli P. Management of complications after pancreaticoduodenectomy in a high volume centre: results on 150 consecutive patients. Dig Surg. 2001;18(6):453-7.

10 Gouma DJ, van Geenen RC, van Gulik TM, de Haan RJ, de Wit LT, Busch OR, et al. Rates of complications and death after pancreaticoduodenectomy: risk factors and the impact of hospital volume. Ann Surg. 2000 Dec;232(6): 786-95.

11 Tien YW, Lee PH, Yang CY, Ho MC, Chiu YF. Risk factors of massive bleeding related to pancreatic leak after pancreaticoduodenectomy. J Am Coll Surg. 2005 Oct;201(4):554-9.

12 Bassi C, Falconi M, Molinari E, Salvia R, Butturini G, Sartori N, et al. Reconstruction by pancreaticojejunostomy versus pancreaticogastrostomy following pancreatectomy: results of a comparative study. Ann Surg. 2005 Dec;242(6):767-71.

13 Grützmann R, Rückert F, Hippe-Davies N, Distler M, Saeger HD. Evaluation of the International Study Group of Pancreatic Surgery definition of post-pancreatectomy hemorrhage in a high-volume center. Surgery. 2012 Apr;151(4):612-20.

14 Wente MN, Veit JA, Bassi C, Dervenis C, Fingerhut A, Gouma DJ, et al. Postpancreatectomy hemorrhage $(\mathrm{PPH})$ : an international study group of pancreatic surgery (ISGPS) definition. Surgery. 2007 Jul;142(1):20-5

15 Pugalenthi A, Protic M, Gonen M, Kingham TP, Angelica MI, Dematteo RP, et al. Postoperative complications and overall survival after pancreaticoduodenectomy for pancreatic ductal adenocarcinoma. J Surg Oncol. 2016 Feb;113(2):188-93.

16 Bassi C, Marchegiani G, Dervenis C, Sarr M, Abu Hilal M, Adham M, et al.; International Study Group on Pancreatic Surgery (ISGPS). The 2016 update of the International Study Group (ISGPS) definition and grading of postoperative pancreatic fistula: 11 Years After. Surgery. 2017 Mar;161(3):584-91.
17 Floortje van Oosten A, Smits FJ, van den Heuvel DA, van Santvoort HC, Molenaar IQ. Diagnosis and management of postpancreatectomy hemorrhage: a systematic review and meta-analysis. HPB (Oxford). 2019 Aug; 21(8):953-61.

18 Biondetti P, Fumarola EM, Ierardi AM, Carrafiello G. Bleeding complications after pancreatic surgery: interventional radiology management. Gland Surg. 2019 Apr;8(2): 150-63.

19 Wells ML, Hansel SL, Bruining DH, Fletcher JG, Froemming AT, Barlow JM, et al. CT for Evaluation of Acute Gastrointestinal Bleeding. Radiographics. 2018 Jul-Aug;38(4):1089-107.

20 Correa-Gallego C, Brennan MF, D’Angelica MI, DeMatteo RP, Fong Y, Kingham TP, et al. Contemporary experience with postpancreatectomy hemorrhage: results of $1,122 \mathrm{pa}-$ tients resected between 2006 and 2011. J Am Coll Surg. 2012 Nov;215(5):616-21.

21 Darnis B, Lebeau R, Chopin-Laly X, Adham M. Postpancreatectomy hemorrhage (PPH): predictors and management from a prospective database. Langenbecks Arch Surg. 2013 Mar;398(3):441-8.

22 Wellner UF, Kulemann B, Lapshyn H, Hoeppner J, Sick O, Makowiec F, et al. Postpancreatectomy hemorrhage-incidence, treatment, and risk factors in over 1,000 pancreatic resections. J Gastrointest Surg. 2014 Mar; 18(3):464-75.

23 Asari S, Matsumoto I, Toyama H, Yamaguchi M, Okada T, Shinzeki M, et al. Recommendation of treatment strategy for postpancreatectomy hemorrhage: lessons from a single-center experience in 35 patients. Pancreatology. 2016 May-Jun;16(3):454-63.

24 Ansari D, Tingstedt B, Lindell G, Keussen I, Ansari D, Andersson R. Hemorrhage after Major Pancreatic Resection: Incidence, Risk Factors, Management, and Outcome. Scand J Surg. 2017 Mar;106(1):47-53.

25 Wolk S, Grützmann R, Rahbari NN, Hoffmann RT, Plodeck V, Weitz J, et al. Management of clinically relevant postpancreatectomy hemorrhage (PPH) over two decades - A comparative study of 1450 consecutive patients undergoing pancreatic resection. Pancreatology. 2017 Nov - Dec;17(6):943-50.

26 Duarte Garcés AA, Andrianello S, Marchegiani G, Piccolo R, Secchettin E, Paiella S, et al. Reappraisal of post-pancreatectomy hemorrhage (PPH) classifications: do we need to redefine grades A and B? HPB (Oxford). 2018 Aug;20(8):702-7.

27 Beyer L, Bonmardion R, Marciano S, Hartung $\mathrm{O}$, Ramis O, Chabert L, et al. Results of nonoperative therapy for delayed hemorrhage after pancreaticoduodenectomy. J Gastrointest Surg. 2009 May;13(5):922-8.

28 Wei HK, Wang SE, Shyr YM, Tseng HS, Tsai WC, Chen TH, et al. Risk factors for postpancreaticoduodenectomy bleeding and finding an innovative approach to treatment. Dig Surg. 2009;26(4):297-305.

29 Mañas-Gómez MJ, Rodríguez-Revuelto R, Balsells-Valls J, Olsina-Kissler JJ, Caralt-Barba M, Pérez-Lafuente M, et al. Post-pancreaticoduodenectomy hemorrhage. Incidence, diagnosis, and treatment. World J Surg. 2011 Nov;35(11):2543-8.
30 Zhang J, Zhu X, Chen H, Qian HG, Leng JH, Qiu H, et al. Management of delayed postpancreaticoduodenectomy arterial bleeding: interventional radiological treatment first. Pancreatology. 2011;11(5):455-63.

31 Feng J, Chen YL, Dong JH, Chen MY, Cai SW, Huang ZQ. Post-pancreaticoduodenectomy hemorrhage: risk factors, managements and outcomes. Hepatobiliary Pancreat Dis Int. 2014 Oct;13(5):513-22.

32 Khalsa BS, Imagawa DK, Chen JI, Dermirjian AN, Yim DB, Findeiss LK. Evolution in the treatment of delayed postpancreatectomy hemorrhage: surgery to interventional radiology. Pancreas. 2015 Aug;44(6):953-8.

33 Wang WG, Fu L, Babu SR, Wang L, Liang CP, Tian BL. Incidence of and risk factors and reinterventions for post-pancreatoduodenectomy hemorrhage: retrospective analysis. Dig Surg. 2018;35(1):19-27.

34 Ding X, Zhu J, Zhu M, Li C, Jian W, Jiang J, et al. Therapeutic management of hemorrhage from visceral artery pseudoaneurysms after pancreatic surgery. J Gastrointest Surg. 2011 Aug;15(8):1417-25.

35 Schäfer M, Heinrich S, Pfammatter T, Clavien PA. Management of delayed major visceral arterial bleeding after pancreatic surgery. HPB (Oxford). 2011 Feb;13(2):132-8.

36 Sanjay P, Kellner M, Tait IS. The role of interventional radiology in the management of surgical complications after pancreatoduodenectomy. HPB (Oxford). 2012 Dec;14(12): 812-7.

37 Stampfl U, Hackert T, Sommer CM, Klauss M, Bellemann N, Siebert S, et al. Superselective embolization for the management of postpancreatectomy hemorrhage: a singlecenter experience in 25 patients. J Vasc Interv Radiol. 2012 Apr;23(4):504-10.

38 Jilesen AP, Tol JA, Busch OR, van Delden OM, van Gulik TM, Nieveen van Dijkum EJ, et al. Emergency management in patients with late hemorrhage after pancreatoduodenectomy for a periampullary tumor. World J Surg. 2014 Sep;38(9):2438-47.

39 Asai K, Zaydfudim V, Truty M, Reid-Lombardo KM, Kendrick M, Que F, et al. Management of a delayed post-pancreatoduodenectomy haemorrhage using endovascular techniques. HPB (Oxford). 2015 Oct;17(10): 902-8.

40 Huo Y, Chi J, Zhang J, Liu W, Liu D, Li J, et al. Endovascular intervention for delayed post-pancreaticoduodenectomy hemorrhage: clinical features and outcomes of transcatheter arterial embolization and covered stent placement. Int J Clin Exp Med. 2015 May; 8(5):7457-66.

41 Ching KC, Santos E, McCluskey KM, Orons PD, Bandi R, Friend CJ, et al. Covered stents and coil embolization for treatment of postpancreatectomy arterial hemorrhage. J Vasc Interv Radiol. 2016 Jan;27(1):73-9.

42 Gaudon C, Soussan J, Louis G, Moutardier V, Gregoire E, Vidal V. Late postpancreatectomy hemorrhage: predictive factors of morbidity and mortality after percutaneous endovascular treatment. Diagn Interv Imaging. 2016 Nov;97(11):1071-7. 
43 Hassold N, Wolfschmidt F, Dierks A, Klein I, Bley T, Kickuth R. Effectiveness and outcome of endovascular therapy for late-onset postpancreatectomy hemorrhage using covered stents and embolization. J Vasc Surg. 2016 Nov;64(5):1373-83.

44 Pottier E, Ronot M, Gaujoux S, Cesaretti M, Barbier L, Sauvanet A, et al. Endovascular management of delayed post-pancreatectomy haemorrhage. Eur Radiol. 2016 Oct;26(10): 3456-65.
45 Bernon MM, Krige JE, Jonas E, Kloppers JC, Burmeister S, Naidoo NG, et al. Severe postpancreatoduodenectomy haemorrhage: an analytical review based on 118 consecutive pancreatoduodenectomy patients in a South African Academic Hospital. S Afr J Surg. 2016 Sep;54(3):23-8.

46 Roulin D, Cerantola Y, Demartines N, Schäfer M. Systematic Review of Delayed Postoperative Hemorrhage after Pancreatic Resection. J Gastrointest Surg. 2011;15:1055-62.
47 Puppala S, Patel J, McPherson S, Nicholson A, Kessel D. Hemorrhagic complications after Whipple surgery: imaging and radiologic intervention. AJR Am J Roentgenol. 2011 Jan; 196(1):192-7.

48 Sato A, Yamada T, Takase K, Matsuhashi T, Higano S, Kaneda T, et al. The fatal risk in hepatic artery embolization for hemostasis after pancreatic and hepatic surgery: importance of collateral arterial pathways. J Vasc Interv Radiol. 2011 Mar;22(3):287-93. 